\title{
Kentsel Alanların ve Kent Donatılarının Tasarımında Ergonomik İlkeler
}

\author{
Atakan Süha KARAYILMAZLAR ${ }^{1 *}$, Selma ÇELIKKYAY ${ }^{1}$ \\ ${ }^{1}$ Bartin Üniversitesi, Orman Fakültesi, Peyzaj Mimarlı̆̆ı Bölümü, BARTIN.
}

\section{Öz}

Kentsel mekân içerisindeki kamusal alanlar, toplumun ortak yaşam alanlarını oluşturmaktadır. Bu alanlar, estetik bir çevre algısı içerisinde güvenlik ve konfor gereksinimini karşıladığı ölçüde, birey için cezbedici sosyalleşme alanları haline gelmektedir. Kent kimliğini ve kültürünü yansıtan kamusal alanların, yaşam kalitesi ve kentlilerin memnuniyeti gibi dinamikleri bakımından kentin karakterini koruyacak, rekabetçi olabilmesini sağlayacak ergonomik tasarım ilkeleri ile düzenlenmesi gerekmektedir.

Buçalışmada, kamusal alanlar, kentsel tasarım, kentsel ergonomi, kent donatıları kavramlarına ve ergonomik kent donatılarına ilişkin kuramsal bilgiler ve ergonomik ilkeler verilmiştir. Ayrıca, ergonominin kentsel tasarımdaki önemi ve ilişkili olduğu faktörler irdelenmiştir.

Anahtar Kelimeler: Kamusal alan, kent donatıları, kentsel ergonomi

\section{Ergonomic Principles in The Design of Urban Spaces and Urban Furnitures}

\begin{abstract}
Public spaces in the urban space constitute the common living spaces of the society. These areas become attractive areas of socialization for an individual to the extent that they meet the need for safety and comfort within an aesthetic perception of the environment. Reflecting the urban identity and culture, public spaces need to be organized according to the ergonomic design principles that will help the urban to be competitive and protect its identity in terms of such dynamics as socio-economic, life quality and satisfaction of city-dwellers. In this study was given theoretical information and ergonomic principles related to public spaces, urban design, urban ergonomics, terms for urban furniture and ergonomic urban furniture. Moreover, the significance of ergonomics in urban design and the related factors were also examined in this study.
\end{abstract}

Keywords: Public space, urban furniture, urban ergonomics. 


\section{Giriş}

1950 'de, dünya nüfusunun \%30’u kentsel alanlarda yaşarken 2050 yılına gelindiğinde dünya nüfusunun \%68'inin kentlerde yaşaması beklenmektedir (UN, 2018). Avrupa ülkelerinde toplam nüfusun üçte ikisinden fazlası kentsel alanlarda yaşamaktadır. Türkiye İstatistik Kurumu Adrese Dayalı Nüfus Kayıt Sistemi verilerine göre, il ve ilçe merkezlerinde ikamet edenlerin oranı ikamet edenlerin oranı 2018 yılında \%92,3, belde ve köylerde yaşayanların oranı ise \%7,7 olarak saptanmıştır (TÜIK, 2018). Aynı zamanda halen köyden kente göç devam etmekte, ilerleyen zamanlarda kentli nüfusunun daha da artacağı tahmin edilmektedir (Çetin vd., 2017).

İnsanların boş zamanlarını geçirecekleri sosyal aktivitelere katılımları günümüzde neredeyse temel ihtiyaçlarından birisi durumuna gelmiştir. Kentlerde yaşayan insanların kültür, bilinç ve gelir düzeylerindeki artışla birlikte insanların beklentileri değişmiş, kentin hava kalitesi, fiziksel çevre, aktivite imkanı, görsel pe y zaj kalitesi gibi etkenler insanların yaşayacakları kenti seçmelerinde etkili olmaya başlamıştır (Oke vd., 1988; Saelens vd., 2003; Sevik vd., 2015). Bu değişim kentsel tasarımın önemini artırmış ve kentsel tasarım günümüzün en önemli konularından birisi durumuna gelmiştir.

Kentsel tasarım, kentsel mekanların kullanıcılarının günlük yaşantılarını ve etkileşimlerini irdelemeyi zorunlu kılmaktadır. $\mathrm{Bu}$ yaklaşımla kent tasarımı fiziksel bir şehir planlaması gibi algılansa bile, kullanıcıların davranışlarına odaklanmış ve insan merkezli amaçlara daha fazla önem göstermektedir. Yerleşim yerlerinin mevcut potansiyellerinin ortaya çıkarılması veya korunması, kent kimliğinin oluşturulması veya kentlere yeni kimlik kazandırılması kavramlarını içermesi açısından bakıldığında bir planlamadan daha çok tasarım yaklaşımıdır (Oğuz vd., 2010).

\section{Kentsel Tasarımda Ergonomi}

Modern toplum, insan ve kültürün doğal çevrenin birer bileşeni olduğunun ve insan sağlığının çevresel koşullarla ayrılmaz bir şekilde bağlantılı olduğunun giderek farkına varmaktadır. Bu nedenle insan - çevre etkileşimi konusunda çalışmalar yapılmakta ve insanın çevre ile etkileşimi pek çok açıdan araştırılmaktadır (Jackson, 2003). Özellikle kamusal alanlar konusunda pek çok çalışma yapılmıştır. Kamusal dış mekânlar, insanların günlük yaşamlarının bir parçasıdır. Bu alanlarda pek çok aktivite gerçekleştirilir ve bu alanlar gerek günlük yaşam ve gerekse gerçekleştirilen aktiviteler vasıtasıyla, toplumu birbirine bağlama konusunda önemli bir rol üstlenirler (Carr. vd., 1995; Madanipour, 1996). Bu alanlarda gerçekleştirilen aktiviteler ve etkileşimler insanları fiziksel ve zihinsel açıdan önemli düzeyde etkilemektedirler (Frumkin, 2001). Ancak bu alanlarda insanların dış mekân konforu, alanın ve donatıların ergonomik yapısıyla yakından ilişkilidir.

Günümüzde kentlerin planlanması bir bütün olarak ele alınmakta ve pek çok meslek disiplininin ortak çalışmasıyla gerçekleştirilmektedir (Golany, 1996). Kentler planlanırken gerek kent içerisinde özel olarak aktivite için ayrılan alanlar (parklar, spor alanları vb.), gerekse insanların günlük yaşamlarında kullandıkları kamusal alanlar (kaldırımlar, caddeler vb.) detaylı olarak, kullanıcıların istek ve ihtiyaçlarına cevap verecek tarzda planlanmalıdır (Montgomery, 1998). Kentsel alanların tasarımı donatı elemanları da düşünülerek bir bütün olarak yapılmalıdır.

Ergonomi; anatomi, antropoloji, fizyoloji, psikoloji, nöroloji ve davranış bilimlerinden yararlanarak insan anatomisi ile tasarımın ilişkilendirilmesi temeline dayanır. Ergonomi, insanın kullandığı objelerin ölçü ve boyutlarını da kapsamaktadır. Ergonomi terimi, insan ve içinde yaşadığı çevre arasındaki uyumu artırma isteği üzerine ortaya çıkan bir terimdir. Kentsel tasarım açısından bakıldığında ergonomi, kamusal alandaki kullanıcının, kenti oluşturan yapılardan kaldırımlara, yaya yollarına ve alanlarına kadar kendini konforlu hissedeceği çevrenin oluşturulması için gerekli tüm spesifikasyonları içerir. Bu nedenle tasarımcı, kent planlamasında kullanıcıların rahatını sağlayacak bir çevre tasarlarken ilgili ergonomik standart ve ölçülerden yararlanmalıdır (Çelikyay ve Karayılmazlar, 2016).

Kentsel ergonomi ise, kamusal alanların ve bu alanlardaki kentsel donatı elemanlarının insan için rahat, güvenilir, elverişli, kullanışlı, toplanma, dinlenme, gezme ve zaman geçirme gibi fiziksel ihtiyaçlarını karşılayabilecek nitelikte tasarlanması ve düzenlenmesini kapsamaktadır. Ergonomik kentsel tasarım, kamusal alanlar ve kentliler arasındaki ilişkiyi gözeterek insan için optimal yararı dikkate alan tasarım uygulamasıdır (Karayılmazlar, 2017).

Yaşadığımız çevrenin, kullandığımız objelerin insanın fiziksel yapısına ve ölçülerine bağlı olarak tasarlanması, mekânsal açıdan olumlu etki yaratmasını sağlamaktadır. Bu bağlamda etkili bir çevre tasarımı, kullanıcıların temel ihtiyaçlarına ve davranışlarına karşılık verebilecek nitelikte olmalıdır. Çünkü insanın ergonomik yapısı ve psikolojik davranışları kentsel planlama ve tasarım aşamasında önemli birer unsurdur (Rutledge, 1985). 
Akad (2007)'ın çalışmasında kentsel açık alanların insanların fiziksel özelliklerine uygunluğunun, mekân kullanımını doğrudan etkilemekte olduğu belirtilmiştir. Tüm bu fiziksel özellikler, açık alanların tasarımında göz önüne alınması gereken tasarım kriterlerini oluşturmaktadır. Fiziksel tasarım kriterlerini görsel uyum ve fiziksel uyum başlıklarına ayırmak mümkündür. Görsel uyum, tasarımın algısal boyutlarını etkileyen estetik değerlerini dikkate alırken, fiziksel uyum ise ergonomi kavramı temelinde, insanın bedensel ve fiziksel özelliklerine uygunluğunu (örneğin; banklarda oturma ölçütleri, merdivenlerde adım atma ölçütlerini) göz önünde bulundurarak yapılan tasarımı ifade etmektedir. Açık alanların kullanımlarının uzun süreli olması ve verimli olarak kullanılması bu kriterlerin tasarım aşamasında ele alınması ve düzenlemelerin ona göre yapılması ile sağlanmaktadır.

Tasarımın genel sınırlarında kullanıcının nitelikleri, ergonomik ilkeleri ile tasarıma temel oluşturan antropometrik özellikleri ve hareketlerinin sınırları birer tasarım ölçütü olarak belirlenmelidir. Kamusal alanlardaki donatı elemanlarının tasarımında bu ergonomik ölçüler daha da önem kazanmaktadır. Toplumların farklı özelliklere sahip olmasından dolayı planlama ve tasarım çalışmalarında uygun verilerin toplanması ve kullanıcı profillerinin belirlenmesi gerekmektedir (Doğan ve Altan, 2007).

\section{Kent Donatıları}

Değişik malzemelerin inşaat ve yapı işlerinde kullanılması sonucunda; sürdürülebilirlik kavramı öne çıkmaktadır. Çapraz tabakalanmış kerestenin (ÇTK) hem sürdürülebilir ve çevreci bir yapı malzemesi olması, üretiminin kontrolünün olması, üretim sırasında istenmeyen kısımların çıkarılması, daha iyi akustik ve termal iletkenliklere sahip olması, beton ve çeliğe göre avantajlarındandır. Üretim teknikleri ve tutkal teknolojilerindeki gelişmeler bu ürünün daha iyi mekanik ve fiziksel özelliklere sahip olmasının önünü açmıştır. Türkiye'de çok fazla tanınmayan hatta üretimi bile yok denecek kadar az olan bu ürünün hakkında farkındalık oluşturmak gerekmektedir. Ülkemizde bu malzemelerin fiziksel, mekanik ve diğer özellikleri ile ilgili akademik araştırmalar ise oldukça sınırlıdır. Çapraz tabakalanmış kereste (ÇTK) yapı kerestesinin tanınırlığının arttırılması, kullanıcılara, mimar mühendis ve sanayicilere bilgi verilmesi, gerekli akademik araştırma sayısının artması ve elde edilen verilerin sanayi toplum kuruluşları ile paylaşılması gerekmektedir. Çapraz tabakalanmış kereste (ÇTK) deprem kuşağında bulunan ülkemiz için oldukça faydalı bir üründür.

\subsection{Oturma Ögeleri}

Bir sokak mobilyası olan oturma ögeleri, bir kamusal alanın tasarımında düzgün şekilde entegre edilmişse, bir kimlik yaratır ve çevresinde bir yer hissi geliştirir. Oturma ve dinlenme amaçlı tasarlanan banklar da kent donatısı olup, bu tip elemanları olabildiğince az parçalı, kullanımı kolay, imalatı basit, iklim koşullarına dayanıklı ve uzun ömürlü olmalıdır. Ayrıca, kullanıcı açısından ergonomik tasarım ve estetiğe sahip olmalıdır. Sadece kullanıldığında değil, kullanılmadığı zamanlarda da bulunduğu ortamın bir parçası olarak görülmelidir. Peyzaj ile uyumlu olarak uygun bir noktada konumlandırılmalı ve üzerine konulduğu zeminin fonksiyonunu destekleyebilecek nitelikte olmalıdır. Oturma ögesinde geçirilmesi istenen süreye bağlı olarak rahatlık ve fonksiyonellik özellikleri belirlenmelidir. (Bulut vd., 2008). Şekil 1'de görüldüğü gibi, oturma yüksekliği 40$50 \mathrm{~cm}$, genişliği 40-50 cm, sırt dayama kısmının yerden yüksekliği ise $70 \mathrm{~cm}$ olmalıdır. Oturma ögesinin sırt kısmının açısı bel bölgesini destekleyecek şekilde 3-5 eğimli olacak şekilde tasarlanmalıdır. (Gülgün ve Altuğ, 2006; URL-1, 2017). Oturma ögeleri engelliler için uygun olarak tasarlanmalı, bankların yanında tekerlekli sandalye kullanan engelliler için alanlar ayrılmalıdır (Kalaycı vd.,2006; Rabare vd., 2009).

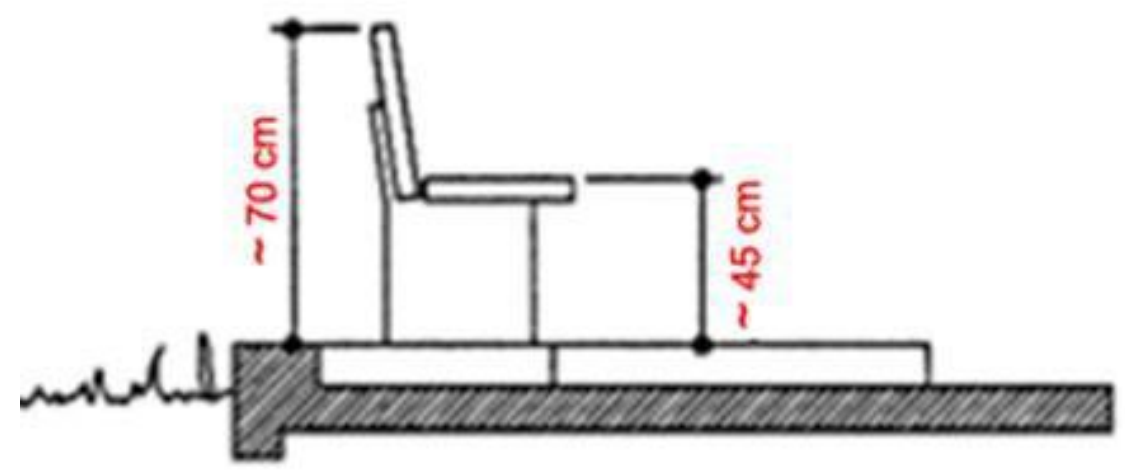

Şekil 1. Oturma Elemanı Standartları (URL-1, 2017). 


\subsection{Aydınlatma Ögeleri}

Dış mekân aydınlatmaları pek çok açıdan önem taşır. Öncelikle alanın güvenliği açısından önemlidir. Yapılan araştırmalar yeterince aydınlatılmayan sokaklarda suç oranının daha yüksek olduğunu ortaya koymaktadır. Dolayısıyla sokak aydınlatmalarında öncelikli konu güvenliktir. Bundan dolayı dış mekân aydınlatma öğelerinde işlevsellik daha da ön plana çıkmaktadır (Painter, 1996; Niaki vd., 2014).

Tasarımsal açıdan ise, dış mekân aydınlatmalarında ana amaç dış mekânı oluşturan elemanların işlevini, biçimini ve uyumunu ortaya çıkaracak nitelikte bir aydınlatmanın yapılmasıdır. Bundan dolayı; dış mekan aydınlatması için yüksek, orta yükseklikte ve alçak aydınlatma ögeleri kullanılmaktadır. Aydınlatma objelerinin dayanıklılığı, sağlamlığı, fiziksel, mimari stil ve peyzajla uyumu gibi görsel özellikleri de dikkate alınmalıdır. Saç, alüminyum, dayanıklı beton, işlem görmüş ahşap, cam, galvanize çelik gibi bir çok malzemeden yapıllabilen tasarımın destek unsurlarından aydınlatma elemanlarının kullanıldıkları mekân ve iklim koşullarına uyumu da ayrıca önemlidir. Örneğin, araç yollarının aydınlatılması, yaya yollarının aydınlatılmasından $\% 50$ daha fazla olmalıdır. Cadde ve sokakların aydınlatılmasında aydınlatma direkleri araç yolunu daha fazla aydınlatacak şekilde simetrik olarak yerleştirilmemelidir (Bulut vd., 2008). Uygun konum ve aydınlığı sağlayacak aydınlatma elemanının yüksekliği yaya yollarında 3-4 m., sokaklarda 4,5-6 m., caddelerde 7,5-9 m. ve anayollarda 10-12 m. olmalıdır (Gülgün ve Altuğ, 2006).

\section{3 Çöp Kutuları}

Başta kentsel alanlar olmak üzere tüm dış mekânlarda çok kullanılan ve birçok şekil ve özellikte tasarlanmış donatı elemanlarından birisi de çöp kutularıdır.

Kentsel alanlarda çöp kutularının doğru noktalarda konumlandırılması önemlidir. Başta fonksiyonelliği olmak üzere diğer tasarım ögeleriyle uyumlu olacak şekilde insan trafiğinin ve yoğunluğunun gözönüne alındığı, kolay erişilebilir noktalara yerleştirilmesi uygun olacaktır. (Bayraktar vd., 2008; Rehan, 2013). Ayrıca, çöp kutusun şekli, boyutları ile kullanımı kolay, diğer donatılarla bütünleşmiş olmasının yanında işlevi gereği içine atılan çöpleri gizleyip koruyabilmesi gereklidir. Çöp kutularının tasarımında, yaralanmalara neden olmayacak malzemeler kullanılmalı, renklendirilmesinde zıt renkler tercih edilmeli ve tek elle kullanılabilecek nitelikte kapaklı olmalıdır. Çöp kutularının konumlandırılmasında yaya hareketleri gözetilmeli, yaya kaldırımı kenarında bordür taşına en az $40 \mathrm{~cm}$ uzaklığında ve en az $90 \mathrm{~cm}$, en çok $120 \mathrm{~cm}$ yükseklikte monte edilmelidir (URL-1, 2017). Şekil 2'de çöp kutusu standartları verilmiştir.

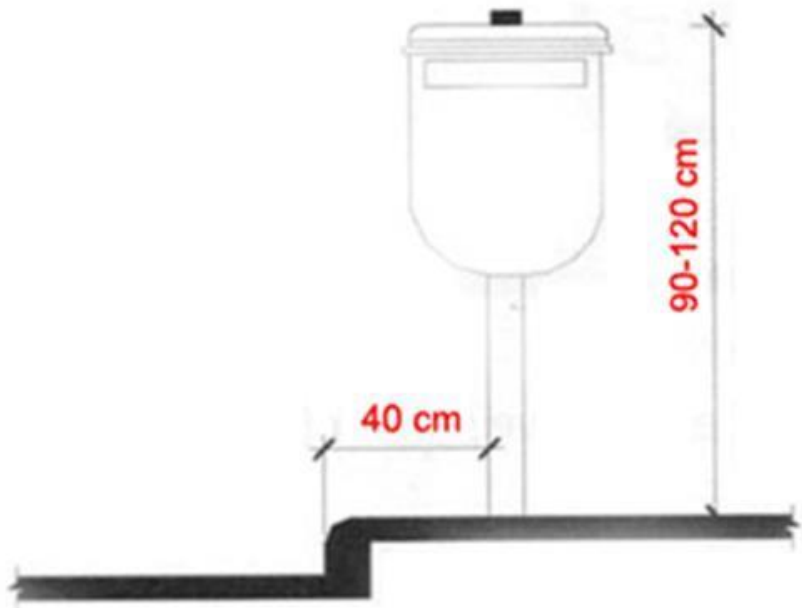

Şekil 2. Çöp Kutusu Standartları (URL-1, 2017).

\subsection{Bitki Kasaları}

Bitkiler kent yaşamında pek çok ekolojik, ekonomik, sosyal ve estetik fonksiyonu yerine getirirler. Bunun yanında insanların psikolojisini olumlu yönde etkilerler. Bundan dolayı kentsel alanlarda bitki kullanımına büyük önem verilmektedir (Yigit vd., 2016; Sevik vd., 2017). Ancak bitki dikilmesi için uygun ve yeterli alan 
bulunmayan yerlerde bitkiler saksı veya kasalar içerisinde yetiştirilmektedir. Bitki kasaları, yoğun yapılaşma ile kısıtlanmış kent merkezi gibi alanlarda, bitkilerin yerlerinin değiştirilmesine olanak veren, bitkileri insandan kaynaklı mekânik etkiden koruyan bakım ve temizliği kolay olan estetik ve işlevsel amaçlı donatı elemanlarıdır. Bitki kasaları, bitki ile birlikte oluşturdukları estetik özellik yanında, dışarıda hizmet veren lokanta, kafe vb. iş yerleri başta olmak üzere çoğu mekân için de sınırlayıcı eleman olarak kullanılmaktadır. Bu donatılar bitkinin fizyolojik isteklerine cevap verecek ve canlılığına devam edebilmesine olanak sağlayacak özelliklere sahip olmalıdır (Sağlık vd., 2014). 180 cm'den daha yüksek bitkisel materyal tercih edilmemelidir. Bitkisel materyalden çevreleme etkisini oluşturması ve sınırlama etkisini sağlaması beklenir (Gülgün ve Altuğ, 2006).

\subsection{Yön ve İşaret Levhaları}

İnsan ve araç trafiğini düzenleme, yönlendirme ve bilgilendirme amacına yönelik tasarlanarak ulaşımı kolaylaştıran diğer bir destek kentsel tasarım ögesi de yön ve işaret levhalarıdır. Bu donatı elemanlarının konumlandırılmasında peyzaj tasarım ve ergonomik standartların yanı sıra; yükseklik, boyut ve konum gibi faktörlere özellikle dikkat edilmelidir. İnsan boyuna eşit veya alçak yapılmamalı, yaya yolları üzerine ve yayaların geçişini engelleyecek şekilde olmamalıdır (Bulut vd., 2008). Yön ve işaret levhalarının da hizmet ettiği amaca uygun şekilde ve renklerde tasarlanmış, yeterli yükseklik ve görülebilir uzaklıkta olması ve trafiği tehlikeye atmayacak biçimde yerleştirilmesi gerekmektedir.

\subsection{Bildirişim Panoları}

Kent tasarımı içerisinde gittikçe yaygınlaşan ve başta reklam olmak üzere bir çok amaçla kullanılan dış mekan bildirişim panoları, bir çok farklı araç ve tekniklerle yapılmaktadır. Özellikle dijital teknolojinin getirmiş olduğu avantajlarla birlikte aydınlatma elemanları ile kullanımı da oldukça yaygınlaşmıştır. Dikkat çekici renk, yazı ve görsellik unsurun yanında diğer donatı elemanları gibi konumlandırılmasında boyut, erişebilirlik ve estetik faktörler de son derece önemlidir. Bu panoların, başta görme engelli yayalar için yerden yüksekliği minimum 220 cm olarak düzenlenmeli (Çelikyay ve Karayılmazlar, 2016; Mitchell ve Suen, 1998). ve diğer kullanıcılar içinde tehlike yaratmayacak şekilde tasarlanıp yerleştirilmelidir.

Kentsel mekân içerisindeki kamusal alanlarda reklam amaçlı panolar dışında, kullanıcıyı yönlendiren ve mekân kullanımını kolaylaştıran, bu amaçla bilgi veren panolara gereksinim vardır. Dolayısıyla, kentlinin özellikle kamusal alandaki dolaşımını ve erişimini kolaylaştıracak bildirişim panolarının yer seçiminde ve tasarımında amaca uygun işlevsellik ve okunabilirlik önem taşımaktadır.

\subsection{Sınırlayıcılar}

Sınırlayıcı elemanların; sınırları çizme, etrafına karşı koruma, mahremiyeti sağlama gibi işlevleri vardır. Farklı malzemelerde ve çeşitli boyutlarda olabilmektedir. Kullanılacak malzemelerin seçiminde estetik, dayanıklılık, çevreye uyum ve işlevsellik gibi özellikleri göz önünde bulundurulmalıdır. Kentlerde daha çok çevreleme elemanı olarak bina bahçelerinde koruma maksadıyla kullanılmaktadır. Genellikle beton, doğal taş ve demir çit olarak yapılan sınırlayıcı elemanlar çok alçak ya da yüksek olmamalı, taşıdığı amaca uygun ölçekte olmalıdır.

\subsection{Su Ögeleri}

İnsanoğlunun var olduğu günden bugüne tartışmasız yaşamın tek ögesi olan su hem iç hem de dış mekanlarda tasarımın, peyzaj düzenlemelerinin fiziksel, biyolojik ve psikolojik bakımdan vazgeçilmez elemanı olmuştur. Açık alanlarda su ögesi kullanımında genellikle o bölgenin iklimi dikkate alınır. Çünkü, peyzaj tasarımında su ögesinin işlenişi yağışlı iklim bölgelerinde kurak yerlere göre daha kolay olmaktadır. Diğer taraftan, suyun insan hayatının bir anlamı olarak yer alması onun insan üzerinde psikolojik ve biyolojik etkisini artırmış ve tasarımın temel unsurlarından birisi olarak yer almıştır. Su, yarattığı görsel etki ile insanların ruhuna canlılık katmakta, bulunduğu mekânın çevresindeki mimari ögelerin detaylarının ortaya çıkmasını sağlamaktadır (Bulut vd., 2008). Bunun dışında su kent ekosistemi içerisinde çok önemli bir yere sahiptir. Peyzaj çalışmalarında kullanılan pek çok su ögesi aynı zamanda kent içerisindeki rutubet miktarını artırır ayrıca, pek çok hayvan için yaşamsal öneme sahiptir (Dwyer vd., 1992; Chiesura, 2004).

\subsection{Estetik Objeler}

Kamusal alanlarda kullanılan estetik objeler bulunduğu mekânla ilişkisi yönünden en önemli donatı 
elemanlarındandır. Sanatçının mekân ve toplum ile olan ilişkisini ortaya çıkaran objeler, alana yüklediği yeni anlamlarla ya da mevcut kimliği yansıtmasıyla bulunduğu mekâna özel bir işlev kazandırır. Estetik objelerin kullanımında mekân ve etrafındaki yapılarla arasındaki oran ilişkisine, mekândaki yer seçimine özellikle dikkat edilmesi gerekir.

\section{Engelliler için kent Donatıları}

zorlaştırmaktadır. Plansız ve hatalı kentsel tasarımlar fiziksel olarak herhangi bir engeli bulunmayan bireyler için bile büyük verim kaybına yol açarken, geçici veya kalıcı engeli bulunan bireyler için aşılması zor sorunlar ortaya çıkarmaktadır. Dünyada olduğu gibi ülkemizde de engelliler ve ailelerinin sorunları ülkemizin temel sorunlarındandır. Engelliler, ek ihtiyaçları olan bireyler olarak sosyal hayattan dışlanmakta ve kendilerini dış ortama kapatmaktadırlar. Engellilerin mekânlardan istifadesi için yaya kaldırımları, yüzey kaplamaları, işaret ve aydınlatma levhaları, kavşak noktaları, merdivenler ve rampalar gereklidir (Bekçi, 2012). Donatı seçiminde ve yapılan planlamada mutlaka engelli bireyler düşünülmeli, onların istek ve ihtiyaçlarına cevap verebilecek tarzda planlama yapılmalı ve donatı seçilmeli (Oğuz, 2000; Dunnett vd., 2002; Foreman vd., 2007), zit renklerle veya doku farklılıkları kullanılarak işaretlenmelidir. Kent mobilyaları keskin ve çıkıntılı kenarlara sahip olmamalı, yürüyüş hattındaki engellerin dokusu hissedilebilmeli, hareketleri engelleyecek işyeri düzenlemelerine izin verilmemelidir. Eğer engellerin çevresinde görme engelliler için dokunulabilir veya renkli işaretler yapılması gerekiyorsa bunların yükseklikleri $70 \mathrm{~cm}$ 'den az olmamalıdır. $220 \mathrm{c} \mathrm{m}$ ' d e n daha alçak olan merdiven altları kapatılmalıdır (URL-1, 2017). Kaldırım üzerindeki oturma yeri ve merdiven altlığı örneği Şekil 3'te verilmiştir.

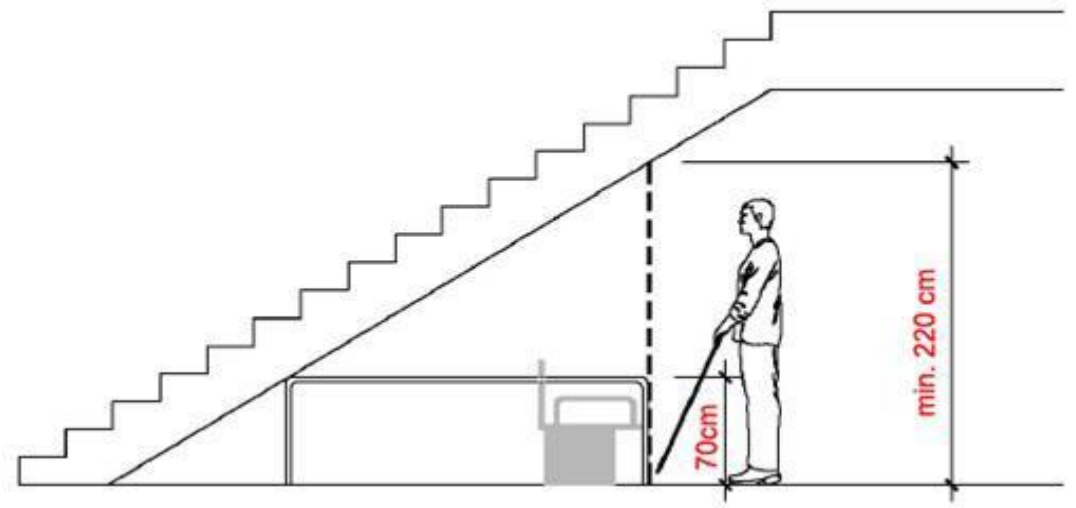

Şekil 3. Kaldırım üzerindeki oturma yeri ve merdiven altlığı (URL-1, 2017).

Görme engellilerin başlarını koruma güvenliği için bina çıkmalarının, her türlü levha, işaret ve tabelaların yerden en az $220 \mathrm{~cm}$ yükseklikte olması gerekmektedir (URL-1, 2017). Levha ve işaret tabelaları konumlandırılmasına ait bir örnek Şekil 4'te gösterilmiştir. 


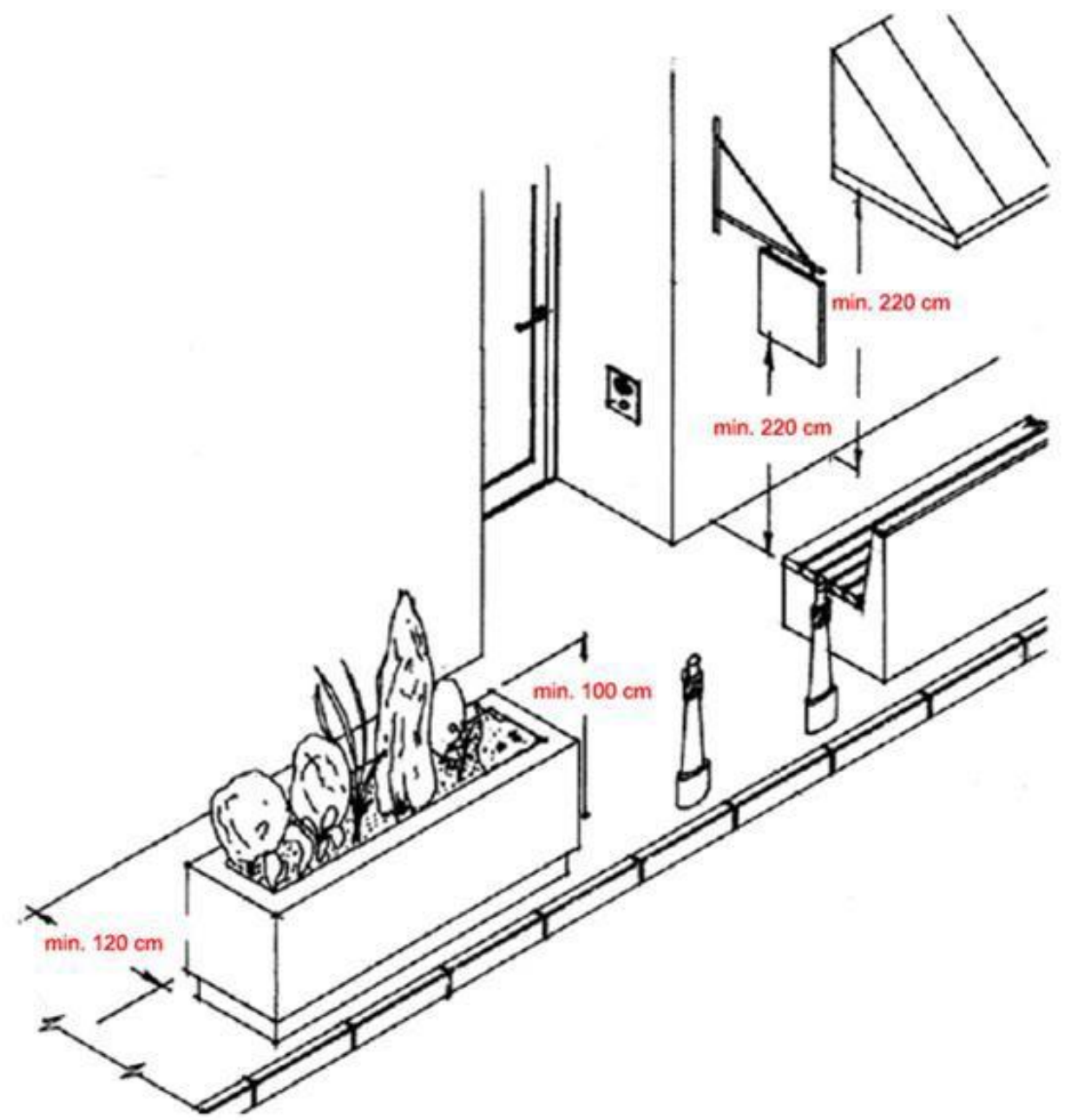

Şekil 4. Levha ve işaret tabelaları konumlandırılması (URL-1, 2017).

En az $150 \mathrm{~cm}$ genişliğinde olması gereken yaya kaldırımlarında, kaldırım genişliğgine bağlı olarak yaya dinlenme alanları ve banklar bulunmalı, bunlar kullanım yoğunluğuna göre 100 m aralıklarla konumlandırılmalıdır. Dinlenme alanlarındaki oturma banklarının yanında Şekil 5'te örneklendiği şekilde tekerlekli sandalyenin yanaşabilmesi için $120 \mathrm{~cm}$ boşluk birakılmalıdır (URL-1, 2017).

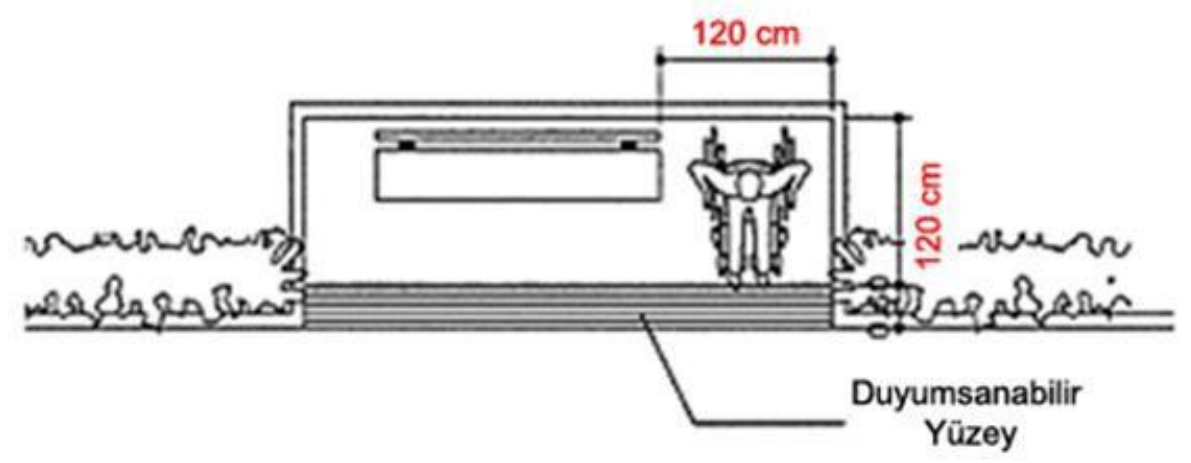

Şekil 5. Dinlenme alanında tekerlekli sandalye boşluğu ölçüleri (URL-1, 2017).

\section{Sonuç ve Öneriler}

Kamusal alanların ve fiziki mekânların türü ve özellikleri ne olursa olsun bunları kullanacak olan insanlardır. Bu 
alanların tasarımı insanın fiziki boyutu ve ölçülerine uygun olarak yapılmalıdır. Tasarımda yapılan ergonomik hatalar kamusal alanların ve kent donatılarının fonksiyonelliğinin yitirilmesine sebep olur.

Kentsel donatıların en önemli özelliği görsel ve işlevsel olmalarıdır. Bu iki özelliğin tüm kentsel donatı elemanlarında bir arada olması istenir. Bu doğrultuda kentsel donatıların kullanımındaki amaç; görsel zenginlik, dayanıklı1ık, yüzeylerde dokusal zenginlik, bakım kolaylı̆̆ı ve estetik değerlerin sağlanmasıdır. Kentsel donatı elemanlarının tasarımında, bir diğer önemli faktör ise; ülkeler ve bölgeler arası kültür, yaş ve cinsiyet farklılıklarını ortadan kaldırmak ya da getirdikleri sorunları ortak çözüme ulaştırmaktır. Böylece ortak kullanıma yönelik tasarlanan bu elemanlar, amacına uygun olarak tüm kentliye hizmet verebilmektedir. Günümüz kentlerinde, kentsel tasarımda donatı elemanları yaşanabilir mekânların oluşturulmasında önem taşımaktadır. Buna karşın, insan yaşamının devamını sağlayan pek çok donatının varlı̆̆ı çoğu zaman görsel kirlilik oluşturmaktadır.

Kentsel mekân ve kamusal alan düzenlemelerinde tasarım ve uygulamalarla ilgili norm, standartlar geliştirilmediğinden birbirleriyle uyum sağlayamayan, kullanıcılara bir anlam ifade edemeyen mekânlar/alanlar oluşmaktadır. Kamusal alanların, estetik ve ergonomik değerlerden yoksun tasarlanması insanların mekân/alan kullanımlarını olumsuz olarak etkilemektedir. Bunun sonucunda, kentlilerin kullanımına uygun olmayan kentsel mekân ve kamusal alanlar ortaya çıkmaktadır. Dolayısıyla kamusal alan tasarımında ve kentsel alanların tasarımında alan ergonomisinin ve kent donatılarının (kent mobilyalarının) ergonomisinin işlevsellikle birlikte öncelikli olarak göz önüne alınması ve ergonomik tasarımın sağlanması gerekmektedir. Bunun için ken donatılarının tasarımında; Donatı elemanının çevre içinde ele alınarak diğer kent ögeleriyle bir bütün içine yerleştirilmesine, görevleriyle uyumlu, yapısal ve işlevsel amaçların gelecekteki gereksinimlere göre belirlenmesine dikkat edilmelidir.

Büyük kentler ve çevrelerinde açık mekânların vazgeçilmez elemanı durumundaki kentsel donatı elemanlarının seçiminde, uygulama alanının; tipi (ticaret alanı, rekreasyon alanı vb.), ölçüsü (boyutları) ve kullanım kapasitesi (hangi elemanların ne miktarda kullanılabileceği) göz önünde tutulmalıdır. Ayrıca, tasarım ve detay önemli bir faktördür; ancak bir diğer önemli faktör de dayanıklılık ve bakım masraflarıdır. Kent merkezi, ticaret alanları ve plazalar için en önemli etken kentsel peyzajda uygun detay ve malzeme kullanımıdır. Tüm bunların yanında estetik görünüm göz önünde bulundurulmalı, donatının kullanımdan önce görsel zevke hitap ettiği unutulmamalıdır. Kentte insanların rahat hareket etmesini, nefes almalarını, görmelerini, yürümelerini, durmalarını, trafik ile güvenli bir ilişki içinde bulunmalarını, yollarını kolay bulmalarını, işaretleri kolay okumalarını sağlayan uygulamalar bütün süslerden ve yapay tasarımlardan daha önde gelen estetik koşullara uymalıdır. Bununla birlikte kentte estetik algı, kullanıcı kitlesinin özelliklerine göre değişmekle birlikte, güzellik ve güzelliğin insan duygularındaki yansımaları olarak da şekillenmektedir. Bu şekillenme ile tasarım çok yönlü bir başarıya ulaşmış demektir.

Kentsel dönüşüm ve yenileme çalışmaları ile daha da önem kazanan kent kalitesi ve karakteri üzerinde etkisi olan kamusal alanların taşıdıkları anlam tasarım düzeyine bağlı bulunmaktadır. Kentlerin karakterinin bir parçası olan kamusal yapılar ve yapısal mekânlar, doğal faktörler ve sosyo-kültürel özellikler sonucu şekillenmektedir.

Kentsel tasarımda, kamusal alanların ve kent donatılarının işlevselliğinin yanı sıra görsel çevrenin estetik ve sanatsal kalitesini arttırarak daha yaşanabilir alanlar oluşturulmasında peyzaj mimarlarına büyük görevler düşmektedir.

\section{Kaynaklar}

1. Akad S (2007). Kentsel Açık Alanlarda Kullanım Sonrası Değerlendirme: İzmir Sahil Bantları Örneği Üzerine Ampirik Bir Araştırma. Yüksek Lisans Tezi, Dokuz Eylül Üniversitesi, Fen Bilimler Enstitüsü, İzmir.

2. Bayraktar N, Tekel A, Ercoşkun Ö Y (2008). Ankara Atatürk Bulvarı Üzerinde Yer Alan Kentsel Donatı Elemanlarının Sınıflandırılması, Değerlendirilmesi ve Kent Kimliği Ilişkisi. Gazi Üniversitesi Mühendislik-Mimarlık Fakültesi Dergisi, 23(1), 105-118. 
3. Bekci B (2012). Fiziksel Engelli Kullanıcılar Için En Uygun Ulaşım Akslarının Erişebilirlik Açıdan Irdelenmesi: Bartın Kenti Örneği. Bartın Orman Fakültesi Dergisi, 14(21), 26-36.

4. Bulut Y, Atabeyoğlu Ö, Yeşil P (2008). Erzurum Kent Merkezi Donatı Elemanlarının Ergonomik Özelliklerinin Değerlendirilmesi Üzerine Bir Araştırma. Tarım Bilimleri Dergisi, 14(2), 131-138.

5. Burgess J, Harrison C M, Limb M (1988). People, Parks and The Urban Green: A Study of Popular Meanings and Values for Open Spaces in The City. Urban studies, 25(6), 455-473.

6. Carr S, Francis M, Rivlin L, Stone A (1995). Public space. Cambridge University Press, Cambridge, ISBN: 0-521-35960-0, 400s.

7. Chiesura A (2004). The role of urban parks for the sustainable city. Landscape and urban planning, 68(1), 129-138.

8. TüIK (2018). Adrese Dayalı Nüfus Kayıt Sistemi Sonuçları. http://tuik.gov.tr/PreHaberBultenleri.do?id=30709 Erişim Tarihi: 10.07.2019

9. Childs M C (2010). Creating Vibrant Public Spaces: Streetscape Design in Commercial andHistoric Districts. Journal of Urban Design, 15:2, 287-289, DOI: 10.1080/13574801003638103.

10. Crankshaw N (2012). Creating Vibrant Public Spaces: Streetscape Design in Commercial and Historic Districts. Island Press.

11. Çelikyay S, Karayılmazlar A S (2016). Bartın Kent Merkezindeki Kamusal Alanların Kentsel Ergonomi ve Kent Kimliği Açısından İncelenmesi. Journal of Bartın Faculty of Forestry, 2016, 18 (2): 224-238.

12. Çetin M, Sevik H, Isinkaralar K (2017). Changes In The Particulate Matter And CO2 Concentrations Based On The Time And Weather Conditions: The Case of Kastamonu. Oxidation Communications, 40 (1-II), 477-485.

13. Doğan C, Altan O (2007). Kamusal Alanda Oturma Eylemi ve Ergonomik İlkeler. YTÜ MİM. Fak. EDergisi, Cilt:2, Say1:3, İstanbul.

14. Dunnett N, Swanwick C, Woolley H (2002). Improving urban parks, play areas and green spaces. London: Department for transport, local government and the regions.

15. Dwyer J F, Mc Pherson E G, Schroeder H W, Rowntree R A (1992). Assessing The Benefits and Costs of the Urban Forest. Journal of Arboriculture, 18, 227-227.

16. Foreman B P, Caesar R R, Parks J, Madden C, Gentilello L M, Shafi S, Diaz-Arrastia R R (2007). Usefulness of The Abbreviated Injury Score and The Injury Severity Score in Comparison to The Glasgow Coma Scale in Predicting Outcome After Traumatic Brain Injury. Journal of Trauma and Acute Care Surgery, 62(4), 946-950.

17. Frumki H (2001). Beyond Toxicity: Human Health and The Natural Environment. Am. J. Prev. Med., 20 (3), 234-240.

18. Golany G S (1996). Urban Design Morphology and Thermal Performance. Atmospheric Environment, 30(3), 455-465.

19. Gülgün B, Altuğ İ (2006). İzmir Kıyı Bandı Uygulamalarında Ergonomik Standartlara Uygunluğun Değerlendirilmesi Üzerine Bir Araştırma. Ege Üniversitesi Ziraat Fakültesi Dergisi, 43(1), 145-156.

20. Jackson L E (2003). The Relationship of Urban Design to Human Health and Condition. Landscape and urban planning, 64(4), 191-200.

21. Kalaycı A, Kutay E L, Kesim G A (2006). Ergonomik Kent ve Engelliler. Kent ve Sağlık Sempozyumu, Bursa, s:239-40.

22. Karayılmazlar A S (2017). Kamusal Alanların Kentsel Ergonomi Açısından Irdelenmesi, Bartın Örneği. Yüksek Lisans Tezi. Bartın Üniversitesi Fen Bilimleri Enstitüsü, Peyzaj Mimarlığı Anabilim Dalı, Bartın.

23. Madanipour A (1996). Design of Urban Design, John Wiley \& Sons Ltd, ISBN: 047196672X, $300 \mathrm{~s}$.

24. Mitchell C G B, Suen S L (1998). Urban Travel, Intelligent Transportation Systems, And The Safety of Elderly and Disabled Travelers. Journal of Urban Technology, 5(1), 17-43.

25. Montgomery J (1998). Making a City: Urbanity, Vitality and Urrban Design. Journal of Urban Design, 3(1), 93-116.

26. Niaki M, Saunier N, Miranda-Moreno L, Amador L, Bruneau J F (2014). Method for Road Lighting Audit and Safety Screening at Urban Intersections. Transportation Research Record: Journal of the Transportation Research Board, (2458), 27-36.

27. Oğuz D (2000). User Surveys of Ankara's Urban Parks. Landscape and urban planning, 52(2), 165171.

28. Oğuz D, Saygı H, Akpınar N (2010). Kentiçi Endüstri Alanlarının Dönüşümüne Bir Model: İzmit/Sekapark A model for the transformation of former industrial sites: İzmit/Sekapark. Coğrafi Bilimler Dergisi, CBD 8(2), 157-167.

29. Oke T R (1988). Street Design and Urban Canopy Layer Climate. Energy and buildings, 11(1), 103-113.

30. Painter K (1996). The influence of Street Lighting Improvements on Crime, Fear and Pedestrian Street 
Use, After Dark. Landscape and urban planning, 35(2), 193-201.

31. Rabare R S, Okech R, Onyango G M (2009). The Role of Urban Parks and Socio- Economic Development: Case Study of Kisumu Kenya. Theoretical and Empirical Researches in Urban Management, 4(3 (12), 22-36.

32. Rehan R. M (2013). Sustainable Streetscape as an Effective Tool In Sustainable Urban Design. HBRC Journal, 9(2), 173-186.

33. Rutledge A J (1985). A Visual Approach to Park Design. John Wiley and Sons, New York, $180 \mathrm{p}$.

34. Sağlık A, Sağlık E, Kelkit A (2014). Kentsel Donatı Elemanlarının Peyzaj Mimarlığı Açısından İrdelenmesi: Çanakkale Kent Merkezi Örneği, 1. Uluslararası Kentsel Planlama- Mimarlık-Tasarım Kongresi, Kocaeli, Türkiye, 8-11 May1s 2014, 1023-1035.

35. Sevik H, Cetin M, Belkayali N (2015). Effects of Forests On Amounts of CO2: Case Study of Kastamonu and Ilgaz Mountain National Parks. Pol J Environ Stud, 24 (1), 253-256.

36. Sevik H, Cetin M, Guney K, Belkayali N (2017). The Influence of House Plants on Indoor CO2. Pol. J. Environ. Stud. Vol. 26, No. 4, 1-9.

37. URL-1 (2017). http://engelsizkent.org/tasarim-rehberi/. Erişim Tarihi: 8.11.2017

38. UN (2018). United Nations World Urbanization Prospects: The 2018 Revision. United Nations Department of Economic and Social Affairs, https://population.un.org/wup/Publications/Files/WUP2018-KeyFacts.pdf Erişim Tarihi: 8.11.2017

39. Yigit N, Sevik H, Cetin M, Kaya N (2016). Determination of the Effect of Drought Stress on the Seed Germination in Some Plant Species. Water Stress in Plants, ISBN:978-953-51-2621-8, chapter 3: p:43-62, InTech, August, 2016.

40. Yücel G F (2013). Street Furniture and Amenities: Designing the User-Oriented Urban Landscape. In Advances in Landscape Architecture. InTech. doi.org/10.5772/55770. 